OPEN ACCESS

Edited by:

Ashfaq Shuaib,

University of Alberta, Canada

Reviewed by:

Raffaele Ornello,

University of L'Aquila, Italy

Rizaldy Taslim Pinzon,

Duta Wacana Christian

University, Indonesia

*Correspondence:

Erqing Chai

Erqingchai@126.com

Futian Tang

tangft@163.com

Specialty section:

This article was submitted to

Stroke,

a section of the journal

Frontiers in Neurology

Received: 14 November 2021

Accepted: 05 January 2022

Published: 15 February 2022

Citation:

Chai E, Chen J, Li C, Zhang X, Fan Z,

Yang S, Zhao K, Li W, Xiao Z, Zhang $Y$

and Tang $F$ (2022) The Efficacy and

Safety of Cilostazol vs. Aspirin for

Secondary Stroke Prevention: A

Systematic Review and Meta-Analysis.

Front. Neurol. 13:814654.

doi: 10.3389/fneur.2022.814654

\section{The Efficacy and Safety of Cilostazol vs. Aspirin for Secondary Stroke Prevention: A Systematic Review and Meta-Analysis}

\author{
Erqing Chai ${ }^{1,2 *}$, Jinhua Chen ${ }^{3}$, Changqing $L^{1}{ }^{1}$, Xue Zhang ${ }^{4}$, Zhiqiang Fan ${ }^{5}$, Shijie Yang ${ }^{5}$, \\ Kaixuan Zhao ${ }^{6}$, Wei Li $^{5}$, Zaixing Xiao ${ }^{5}$, Yichuan Zhang ${ }^{6}$ and Futian Tang ${ }^{7 *}$ \\ ${ }^{1}$ Cerebrovascular Disease Center, Gansu Provincial Hospital, Lanzhou, China, ${ }^{2}$ Emergency General Hospital, Beijing, China, \\ ${ }^{3}$ The First School of Clinical Medicine, Lanzhou University, Lanzhou, China, ${ }^{4}$ Intensive Care Unit 1, Gansu Provincial Hospital, \\ Lanzhou, China, ${ }^{5}$ First Clinical Medical College, Gansu University of Chinese Medicine, Lanzhou, China, ${ }^{6}$ School of Clinical \\ Medicine, Ningxia Medical University, Ningxia, China, ${ }^{7}$ Key Laboratory of Gansu Digestive System Tumor, Lanzhou University \\ Second Hospital, Lanzhou, China
}

Background: Cilostazol is often used in Asia-Pacific countries for stroke prevention. The current systematic review and meta-analysis aimed to evaluate the effectiveness, safety, and adverse outcomes of cilostazol monotherapy compared to aspirin monotherapy for secondary stroke prevention.

Methods: The researchers conducted a comprehensive research in multiple databases (PubMed, Embase, and Cochrane library) of randomized controlled trials from conception to December 2020. The primary efficacy outcome was the occurrence of any stroke, the primary safety outcome was the bleeding risk, and the primary adverse outcome was the rate of headache and dizziness. The Mantel-Haenszel method was used to calculate a random-effects prediction. Cilostazol and aspirin were compared using a pooled risk assessment with 95\% Cls.

Results: Six studies involving 5,617 patients were included in this review. Compared with aspirin monotherapy, cilostazol was associated with significantly lower rates of any strokes (RR: 0.67; 95\% Cl: 0.55-0.82) and significantly lower bleeding rates [risk ratio (RR): 0.53; 95\% Cl: 0.37-0.74]. However, compared with aspirin monotherapy, cilostazol was associated with significantly higher rates of headache (RR: $1.77 ; 95 \% \mathrm{Cl}: 1.41-2.20)$ and dizziness (RR: 1.28; 95\% Cl: 1.08-1.52).

Conclusions: Consistent with previous studies, cilostazol monotherapy is superior to aspirin monotherapy in reducing the rate of any strokes and the bleeding risk after having a stroke. However, the use of cilostazol monotherapy is associated with several adverse life outcomes such as headaches and dizziness.

Keywords: stroke prevention, efficacy and safety, cilostazol, aspirin, systematic review and meta-analysis 


\section{INTRODUCTION}

A stroke has main clinical manifestations of cerebral ischemia and hemorrhagic injury, having a very high mortality and disability rate $(1,2)$. Antiplatelets are the major therapy for the secondary stroke prevention (3). Aspirin and cilostazol are the most commonly used antiplatelet agents (4). Most patients who have had a stroke are given aspirin (5). According to two major randomized clinical studies of aspirin in acute ischemic stroke, aspirin decreased the risk of early chronic stroke by $\sim 12 \%$ at 2-4 weeks (6). However, aspirin-related cerebral hemorrhage is a complication that is currently of concern (5). Cilostazol was reported to be efficacious for the prevention of stroke recurrence (4), which might be related to the various mechanisms, such as anti-platelet aggregation, anti-atherosclerosis, promotion of vascular endothelial recovery, cell apoptosis inhibition, and practical value for the prevention and treatment of ischemic stroke $(5,7,8)$. Studies have shown that cilostazol can be used as a drug to treat ischemic strokes and as a preventive drug for recurrence (9). Shinohara et al. (4) reported that the primary endpoint for prevention of secondary stroke occurred at yearly rates of $2.76 \%$ in the cilostazol group and $3.71 \%$ in the aspirin group ( $p=0.0357)$.

The previous meta-analysis primarily focused on comparing the efficacy and safety of cilostazol monotherapy or dual therapy with clopidogrel and aspirin monotherapy (10-12). However, there is no meta-analysis comparing cilostazol monotherapy to aspirin monotherapy as secondary prevention after stroke and in regard to cilostazol's side effects. Therefore, the researchers conducted a systematic review and meta-analysis to evaluate the efficacy and safety of cilostazol monotherapy compared to aspirin therapy. The researchers will further identify the frequency of the adverse side effects caused by these two treatment arms.

\section{METHODS}

\section{Data Sources}

The Preferred Reporting Items for Systematic Reviews and Meta-Analyses (PRISMA) checklist was used to perform our meta-analysis based on the Preferred Reporting Elements for Systematic Assessments (13). Searches were conducted in the following electronic databases from conception to December 2020: PubMed, Embase, and the Cochrane Library. The researchers searched with the following headings: "stroke," "acute ischemic stroke," "TIA," "secondary prevention," "aspirin," AND "cilostazol." The gray literature was searched through OpenGrey and Google Scholar. After searches, all relevant citations were saved in a bibliographic reference manager (EndNote, x9 version, Thomson Reuters). Duplicated results were considered only one time. The titles and abstracts that did not adhere to the established eligibility criteria were excluded. The resulting articles were evaluated and judged by their full text. Additional citations were sought from the analysis of the reference list of all the articles previously selected. The selection process was conducted by two examiners (EC and CL) and checked by a third examiner (FT) in cases of disagreements.

\section{Selection Criteria and Data Extraction}

The inclusion criteria were: (1) randomized controlled studies, (2) a comparison of cilostazol monotherapy with aspirin monotherapy, (3) the efficacy outcomes including recurrent stroke reported, and (4) the adverse outcomes. A total of six studies met the criteria. The exclusion criteria included: (1) non-randomized controlled trials, (2) the cilostazol combination therapy (clopidogrel or aspirin) with an aspirin combination therapy (clopidogrel), (3) only reported efficacy and safety outcomes and no adverse outcomes reported. Two authors independently conducted the research and performed the data extraction (Figure 1).

\section{Outcomes Measured}

The primary efficacy outcome was the occurrence of any stroke (including ischemic stroke and hemorrhagic stroke); the secondary efficacy outcome includes the occurrence of ischemic stroke. The primary safety outcome was intracranial hemorrhage, including subarachnoid hemorrhage and subarachnoid hemorrhage, and other safety outcomes, including bleeding, vascular death, and all-cause mortality. The primary adverse outcome is the headache; the secondary adverse outcome is dizziness where both outcomes include tachycardia and palpitation.

\section{Assessment of Risk of Bias}

Two reviewers (EC and CL) independently evaluated the quality of the included randomized control trials (RCTs) using a modified version of the Cochrane risk of bias tool (RoB2) for randomized trials to address the risk of bias. Any disagreements between the rater of pieces of evidence are resolved by a third examiner (FT) (14). The researchers graded the evidence quality based on random sequence generation, allocation concealment, participant and staff blindness, outcome assessor blinding, missing outcome data (which rated as high risk of bias if missing data exceed 10\%), and other biases. The findings were presented using the MAGICapp (15) (Figure 2).

\section{Quality of Evidence}

The GRADE form was used to evaluate the quality of research (14). We graded the quality of research as high, moderate, low, or very poor for each outcome based on imprecision, inconsistency, indirectness, publication bias, and overall risk of bias.

\section{Statistical Analysis}

For dichotomous results, the researchers used the MantelHaenszel method to measure overview risk ratios (RRs) and 95\% CIs and used a random-effects model to account for the betweenstudy heterogeneity. The researchers further used the Cochrane $\mathrm{Q}$ statistics and the $\mathrm{I} 2$ test to determine the heterogeneity of 


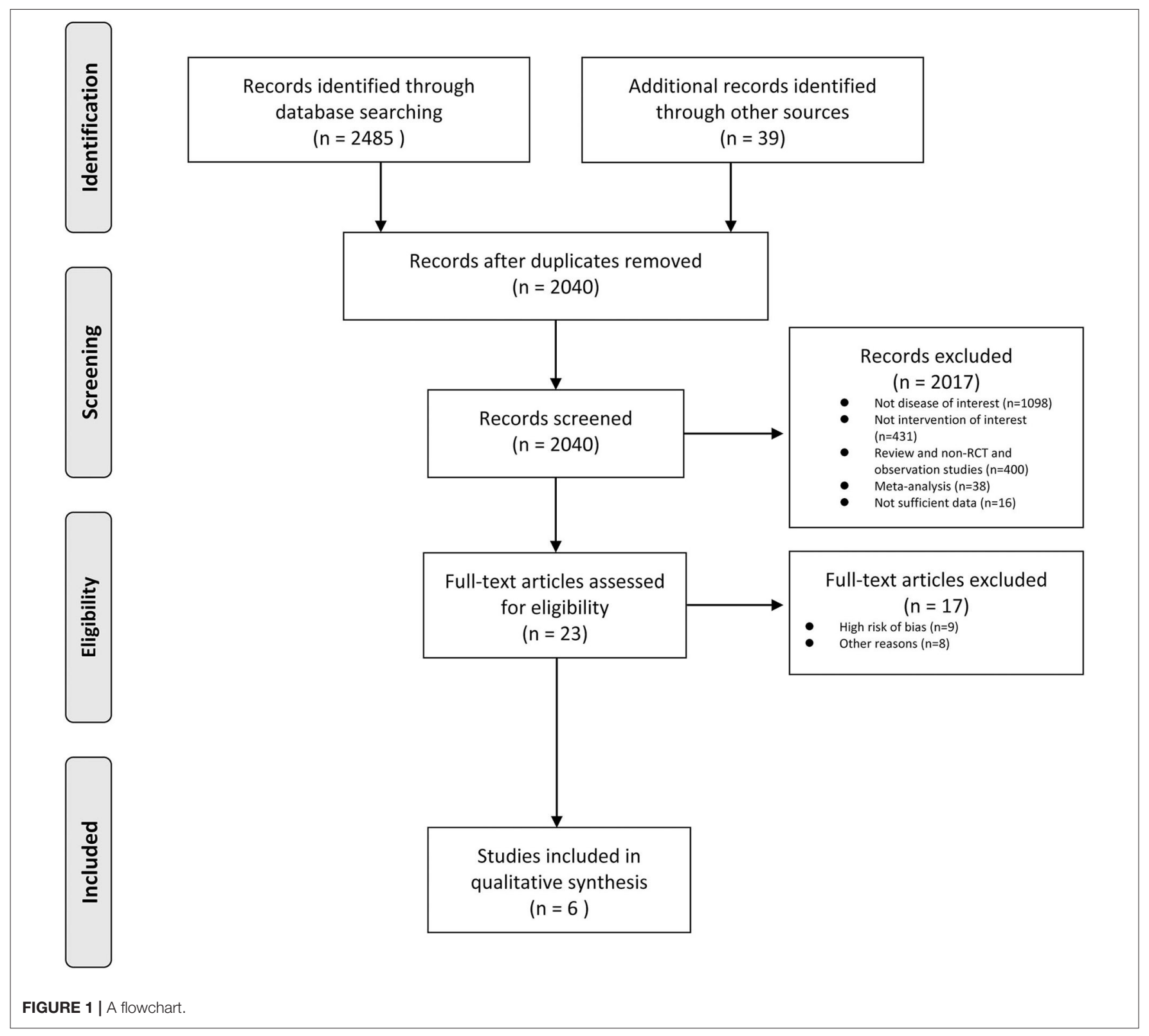

\section{$\underline{\text { Study ID }}$}

Huang et al., 2008

Guo et al., 2009

Lee et al., 2011

Shinohara e al., 2010

Lee et al., 2017

Kim et al., 2018

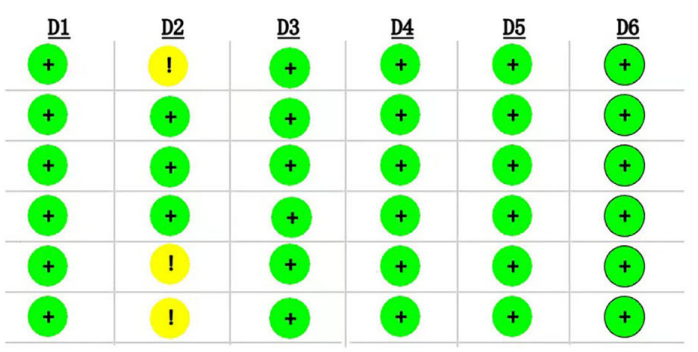

Low risk

! Some concerns

- High risk

D1 Random sequence generation

D2 allocation concealment

D3 participants and staff blindeness

D4 out come assessor bliding

D5 insufficient outcome data

D6 $\quad$ other bias

FIGURE 2 | Bias assessment. 
TABLE 1 | Characteristics of included studies.

\begin{tabular}{|c|c|c|c|c|c|c|c|c|c|c|}
\hline \multirow[t]{2}{*}{ References } & \multirow[t]{2}{*}{ Design } & \multirow[t]{2}{*}{ Study period } & \multirow{2}{*}{$\begin{array}{l}\text { Follow-up } \\
\text { (months) }\end{array}$} & \multicolumn{2}{|c|}{ Medications } & \multirow[t]{2}{*}{ Total No. } & \multirow{2}{*}{$\begin{array}{l}\text { Primary } \\
\text { outcome }\end{array}$} & \multirow[t]{2}{*}{ Cilostazol } & \multirow[t]{2}{*}{ Aspirin } & \multirow[t]{2}{*}{$P$-value } \\
\hline & & & & Cilostazol & Aspirin & & & & & \\
\hline $\begin{array}{l}\text { Huang et al. } \\
\text { (5) }\end{array}$ & $\begin{array}{l}\text { Multicenter } \\
\text { Double-blind }\end{array}$ & $\begin{array}{l}\text { May 2004- } \\
\text { Dec. } 2004\end{array}$ & $12-18$ & $\begin{array}{l}100 \mathrm{mg} \\
\text { twice/day }\end{array}$ & 100 mg/day & $\begin{array}{l}N=720 \\
- \text { Ischemic within } \\
\text { previous } \\
1-6 \text { months }\end{array}$ & $\begin{array}{l}\text { Occurrence of } \\
\text { stroke }\end{array}$ & 0.28 & 0.85 & 0.18 \\
\hline Guo et al. (16) & & $\begin{array}{l}\text { May 2004- } \\
\text { Dec. } 2005\end{array}$ & 12 & $\begin{array}{l}100 \mathrm{mg} \\
\text { twice/day }\end{array}$ & 100 twice/day & $\begin{array}{l}N=68 \\
\text { - Ischemic within } \\
1-6 \text { months }\end{array}$ & $\begin{array}{l}\text { Cerebro- } \\
\text { vascular } \\
\text { aggravation }\end{array}$ & $1 \%$ & $1 \%$ & 0.90 \\
\hline Lee et al. (8) & $\begin{array}{l}\text { Double blind } \\
\text { Non-inferiority }\end{array}$ & $\begin{array}{l}\text { Jan.2006- } \\
\text { Mar. } 2008\end{array}$ & 3 & 200 mg/day & 300 mg/day & $N=458$ & $\begin{array}{l}\mathrm{mRS} \text { score of } \\
0-2 \text { at } 90 \text { days }\end{array}$ & 173/231 & $165 / 227$ & 0.90 \\
\hline $\begin{array}{l}\text { Shinohara et } \\
\text { al. (4) }\end{array}$ & $\begin{array}{l}\text { Randomized } \\
\text { Double-blind } \\
\text { Non-inferiority }\end{array}$ & $\begin{array}{l}\text { Dec. 2003- } \\
\text { Oct. } 2006\end{array}$ & $29^{*}$ & $\begin{array}{l}100 \mathrm{mg} \\
\text { twice/day }\end{array}$ & 81 mg/day & $\begin{array}{l}N=2,757 \\
\text { - Non-cardioem- } \\
\text { bolic cerebral } \\
\text { infarction } \\
\text { previous } \\
26 \text { weeks }\end{array}$ & Recurrent stroke & $82 / 1,337$ & $113 / 1,335$ & 0.036 \\
\hline Lee et al. (7) & Double-blind & $\begin{array}{l}\text { March 2012- } \\
\text { Oct. } 2014\end{array}$ & 3 & $\begin{array}{l}100 \mathrm{mg} \\
\text { twice/day }\end{array}$ & 100 mg/day & $\begin{array}{l}N=80 \\
\text { - Acute } \\
\text { ischemic stroke/TIA }\end{array}$ & $\begin{array}{l}\text { Serious adverse } \\
\text { events }\end{array}$ & $2 / 40$ & $5 / 40$ & 0.235 \\
\hline Kim et al. (17) & Multicenter & $\begin{array}{l}\text { Aug 2009- } \\
\text { Aug } 2015\end{array}$ & $22.8^{\star \star}$ & $\begin{array}{l}100 \mathrm{mg} \\
\text { twice/day }\end{array}$ & 100 mg/day & $\begin{array}{l}N=1,534 \\
\text { - Non- } \\
\text { cardioembolic } \\
\text { ischemic } \\
\text { stroke/TIA } \\
\text { within } 180 \text { days }\end{array}$ & $\begin{array}{l}\text { Composite of } \\
\text { major vascular } \\
\text { events }\end{array}$ & $63 / 755$ & $80 / 757$ & 0.008 \\
\hline
\end{tabular}

${ }^{*}$ Mean follow-up.

**Median follow-up 
the included studies and used the RevMan 5.4 to conduct the meta-analysis.

\section{RESULTS}

\section{Study Identification and Trial Characteristics}

Figure 1 presents the findings of the researchers' included studies. A total of six studies $(4,5,7,8,16,17)$ were included in the analysis with a total of 5,617 patients. All studies compared cilostazol monotherapy to aspirin monotherapy. The researchers found 2,524 documents in electronic libraries, 507 of which were duplicates and further reviewed 23 full-text articles with omissions on the 2017 records, depending on the title and abstract.

Table 1 summarizes the characteristics of the six included studies. Four included trials administered with cilostazol at $100 \mathrm{mg}$ two times/day and aspirin at $100 \mathrm{mg} /$ day. One of the trials administered cilostazol at a dose of $200 \mathrm{mg} /$ day and aspirin at $300 \mathrm{mg} /$ day. Another study included a trial administered with cilostazol at $200 \mathrm{mg} /$ day and aspirin at $100 \mathrm{mg}$ /day. Moreover, one included study administered cilostazol at a dose of $100 \mathrm{mg}$ two times daily and aspirin at $81 \mathrm{mg} /$ day. All studies were conducted in Asian countries as a result of cilostazol being mainly used in Asian countries. The patient demographics are summarized in Table 2.

\section{Risk of Bias}

Figure 2 presented the risks of bias of the six included RCT studies. The appropriateness in estimating the effect of assignment to intervention is unclear in three RCTs. Otherwise, the overall risks of bias are low for the six included RCTs.

\section{Efficacy Outcomes}

Compared with aspirin alone, a total of four studies with 5,260 patients showed that cilostazol monotherapy significantly reduced the risk of any stroke (RR: 0.67 ; 95\% CI: $0.55-0.82, p<$ 0.0001 ) (Figure 3A). Four studies with 2,260 patients showed that cilostazol monotherapy was also associated with a lower ischemic stroke rate, however the results recorded were not significantly different (RR: 0.76; 95\% CI: 0.54-1.07, $p=0.11$ ) (Figure 3B).

\section{Safety Outcomes}

Compared with aspirin alone, a total of four studies with 2,109 patients showed that cilostazol monotherapy significantly reduced intracranial bleeding (RR: 0.46 ; 95\% CI: $0.22-0.94, p$ $=0.03$ ) (Figure $4 \mathrm{~A}$ ) and significantly reduced any bleeding risk (RR: 0.53; 95\% CI: 0.37-0.74, $p=0.0002$ ) (Figure 4B). However, there was no significant difference between cilostazol and aspirin alone for vascular death and all-cause mortality (RR: 1.60; 95\% CI: $0.60-4.26 p=0.35$ ) (Figure 4C) (RR: 0.91; 95\% CI: 0.60-1.37, $p=0.64)($ Figure 4D).

\section{Adverse Outcomes}

A total of six studies involving 4,740 patients showed that cilostazol was associated with a higher incidence of headache

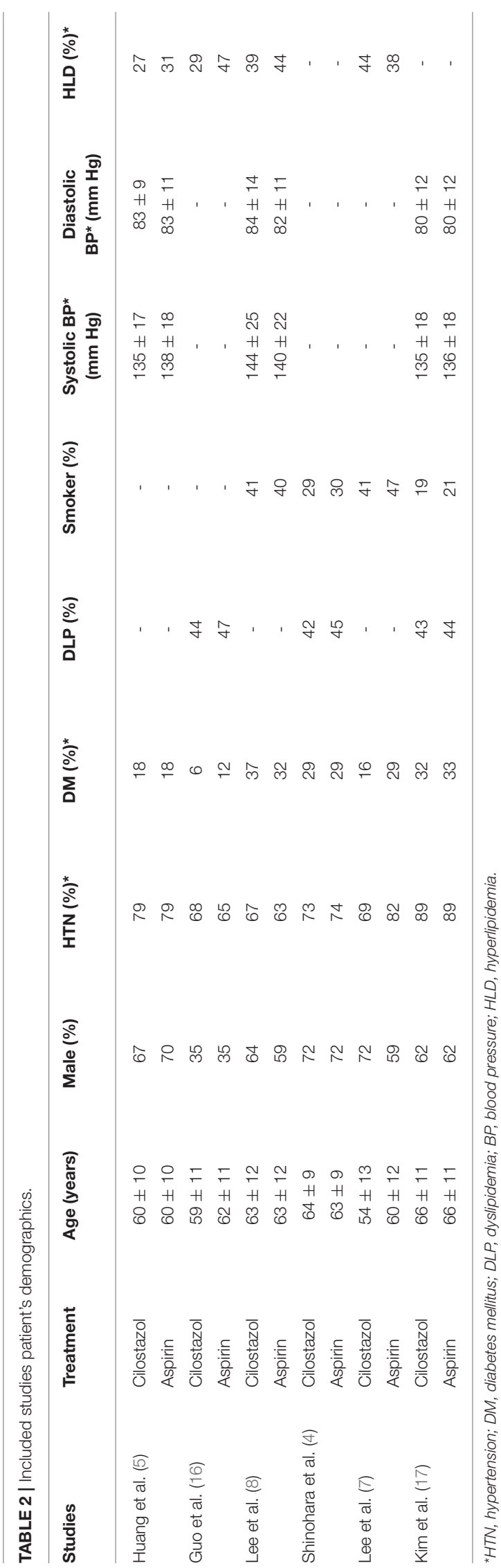


A

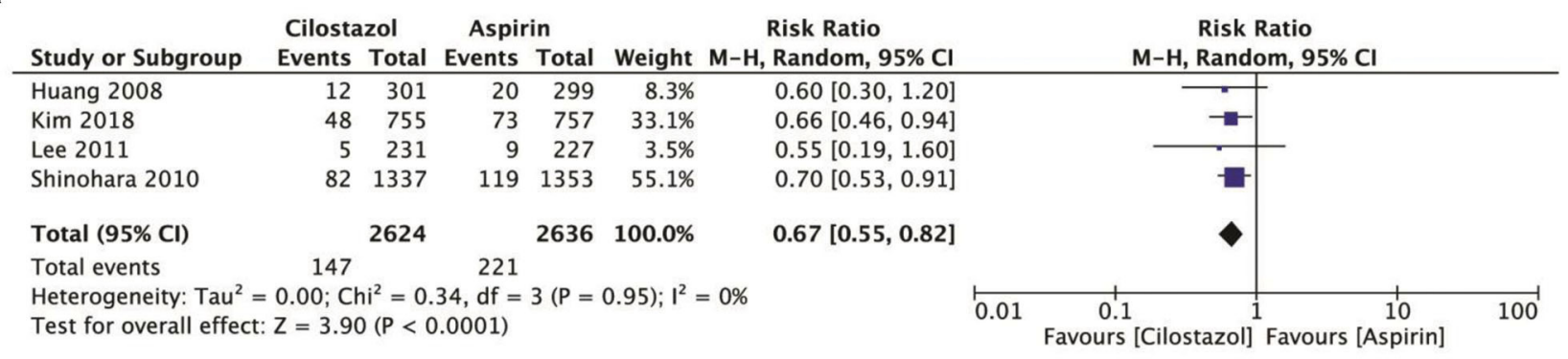

B

\begin{tabular}{|c|c|c|c|c|c|c|}
\hline Study or Subgroup & $\begin{array}{l}\text { Cilosta } \\
\text { Events }\end{array}$ & $\begin{array}{l}\text { zol } \\
\text { Total }\end{array}$ & $\begin{array}{l}\text { Aspir } \\
\text { Events }\end{array}$ & $\begin{array}{l}\text { in } \\
\text { Total }\end{array}$ & Weight & $\begin{array}{c}\text { Risk Ratio } \\
\text { M-H, Random, } 95 \% \mathrm{C} \\
\end{array}$ \\
\hline Guo 2009 & 2 & 34 & 1 & 34 & $2.1 \%$ & $2.00[0.19,21.03$ \\
\hline Huang 2008 & 11 & 301 & 15 & 299 & $20.5 \%$ & $0.73[0.34,1.56$ \\
\hline Kim 2018 & 40 & 755 & 55 & 757 & $76.2 \%$ & $49,1.08$ \\
\hline Lee 2017 & 1 & 40 & 0 & 40 & $1.2 \%$ & $3.00[0.13,71.51$ \\
\hline Total $(95 \% \mathrm{Cl})$ & & 1130 & & 1130 & $100.0 \%$ & $0.76[0.54,1.07$ \\
\hline Total events & 54 & & 71 & & & \\
\hline
\end{tabular}

FIGURE 3 | (A) A forest plot of comparison: any stroke; (B) A forest plot of comparison: ischemic stroke.

compared with aspirin monotherapy (RR: 1.77; 95\% CI: $1.41-$ 2.21, $p<0.00001$ ) (Figure 5A), while cilostazol also significantly increased the frequency of dizziness (RR: 1.28; 95\% CI: $1.08-$ 1.52, $p=0.005$ ) (Figure 5B). Two studies with 3,391 patients showed that cilostazol monotherapy significantly increased the tachycardia risk compared to aspirin monotherapy (RR: 3.94; 95\% CI: 2.62-5.93, $p<0.00001$ ) (Figure 5C). However, four studies with 4,601 patients showed that cilostazol did not significantly increase the palpitation frequency compared to aspirin monotherapy (RR: 1.47 ; 95\% CI: $0.34-6.31, p=0.61$ ) (Figure 5D).

\section{DISCUSSION}

The researchers made some potentially valuable findings in this meta-analysis of six RCTs $(n=29,032)$ comparing cilostazol monotherapy to aspirin monotherapy. First, in patients with stroke, compared with aspirin, cilostazol significantly reduces any stroke incidence while reducing intracranial bleeding or any bleeding risks and does not significantly increase vascular death or death events. Second, although cilostazol alone is more efficient and safer than aspirin alone, cilostazol increases adverse events, primarily significantly increasing the incidence of headache, dizziness, and tachycardia. Similar results were found showing that the patients who received cilostazol had a $30 \%$ lower risk of persistent ischemic stroke, a 59\% lower risk of intracranial hemorrhage, and a $29 \%$ lower risk of bleeding than patients who received aspirin (18). In addition, the current meta-analysis accounts for the adverse events in the results, which are the strength of this meta-analysis. Additionally, low heterogeneity $\left(I^{2}\right.$ $=0-31 \%)$ was observed in the evidence.

Stroke is the most common cause of disabilities and death (3). Despite the efforts of researchers and pharmaceutical companies, the risk of stroke recurrence remains high (19). The use of antiplatelet agents is recommended to reduce the long-term risk of non-cardioembolic ischemic stroke or TIA (20). Aspirin is a commonly used antiplatelet agent for secondary stroke prevention, but its benefit must be weighed against its bleeding risks, particularly in the aging population (20). It has been proved that aspirin is safe and beneficial in preventing stroke recurrence, but aspirin can only reduce recurrent vascular events by $20 \%$ (21). Previous meta-analyses have evaluated the effect of aspirin combined with clopidogrel on secondary stroke prevention, but, because of the high bleeding complications, no net benefit was found (22-28). Studies have recently found that it is more beneficial for acute high-risk patients treated with ticagrelor and aspirin than aspirin alone (29). Clearly, the optimal antiplatelet regimen, particularly in individuals at high risk for cerebral hemorrhages, such as those with a high burden of cerebral small-vessel disease, remains unclear and needs further investigation in well-designed clinical trials.

This study shows that Kim et al. did not find a significant effect of cilostazol and aspirin on intracranial hemorrhage, which may be due to their fragile small vessels and may lead to a greater incidence of intracranial bleeding (17). Similar findings were reported by Shinohara et al. (4); there was no significant intracranial hemorrhage between cilostazol and aspirin due to a high proportion of patients with a lacunar stroke in their study. 


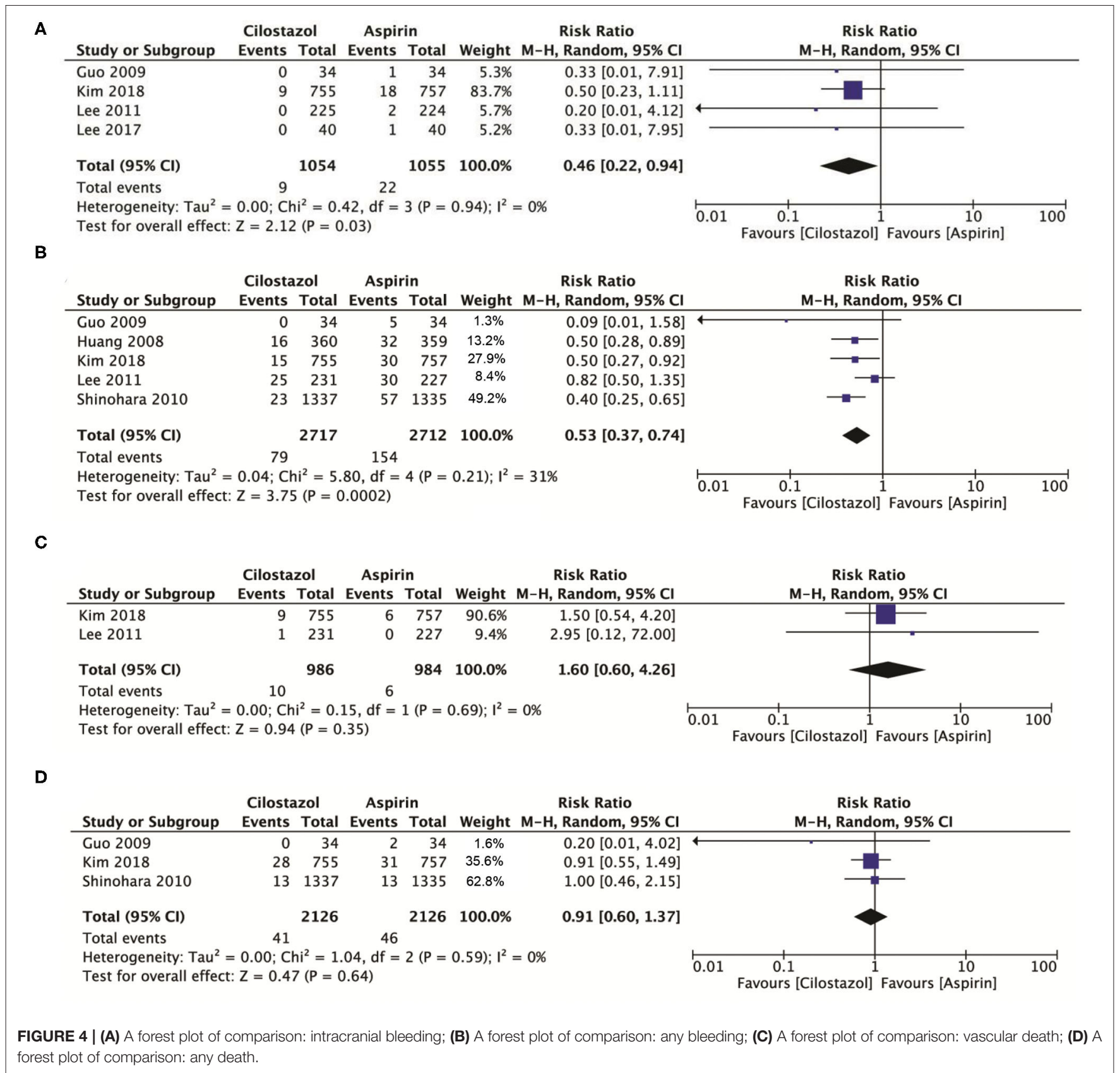

Adverse events, including headaches and dizziness, occurred more frequently in the cilostazol group than in the aspirin group, but none were severe and all symptoms resolved after discontinuation or dose tapering of cilostazol. A study showed that some patients might avoid the adverse events caused by cilostazol by incremental increases in dose from $50 \mathrm{mg}$ (4).

As a new type of antiplatelet inhibitor, cilostazol has antiarterial thrombosis, prevents atherosclerosis, and improves vascular endothelial function (30-32). It can also regulate blood lipids and expand arterial blood vessels to stabilize plaques (33). It has a wide range of applications in treating peripheral vascular disease, preventing stent restenosis and thrombosis after PCI
(34), and secondary prevention of ischemic stroke $(16,35)$. It is more suitable for aspirin-resistant or intolerant people, especially Asians (36).

Cilostazol is a selective inhibitor of phosphodiesterase, which increases intracellular activity, thereby inhibiting platelet aggregation (37-39). In some respects, the drug is a potent drug that can replace aspirin. For example, in previous clinical trials and meta-analyses, cilostazol significantly reduced the risk of stroke recurrence and lower bleeding events compared to aspirin $(40,41)$. Moreover, our current meta-analysis is in line with previous meta-analyses that found cilostazol to be more beneficial in patients with ischemic stroke $(18,42)$. 


\section{A}

\begin{tabular}{|c|c|c|c|c|c|c|}
\hline \multirow[b]{2}{*}{ Study or Subgroup } & \multicolumn{2}{|c|}{ Cilostazol } & \multicolumn{2}{|c|}{ Aspirin } & \multirow[b]{2}{*}{ Weight } & \multirow{2}{*}{$\begin{array}{c}\text { Risk Ratio } \\
\text { M-H, Random, } 95 \% \mathrm{Cl}\end{array}$} \\
\hline & Events & Total & Events & Total & & \\
\hline Guo 2009 & 8 & 34 & 2 & 34 & $1.4 \%$ & $4.00[0.92,17.48]$ \\
\hline Huang 2008 & 49 & 360 & 19 & 359 & $15.1 \%$ & $2.57[1.55,4.28]$ \\
\hline Kim 2018 & 59 & 378 & 34 & 383 & $16.0 \%$ & $1.76[1.18,2.62]$ \\
\hline Lee 2011 & 114 & 225 & 71 & 224 & $9.5 \%$ & $1.60[1.27,2.01]$ \\
\hline Lee 2017 & 14 & 40 & 3 & 40 & $1.7 \%$ & $4.67[1.45,15.00]$ \\
\hline Shinohara 2010 & 313 & 1337 & 217 & 1335 & $56.3 \%$ & $1.44[1.23,1.68]$ \\
\hline Total $(95 \% \mathrm{Cl})$ & & 2374 & & 2375 & $100.0 \%$ & $1.77[1.41,2.21]$ \\
\hline Total events & 557 & & 346 & & & \\
\hline
\end{tabular}

Test for overall effect: $Z=4.98(P<0.00001)$

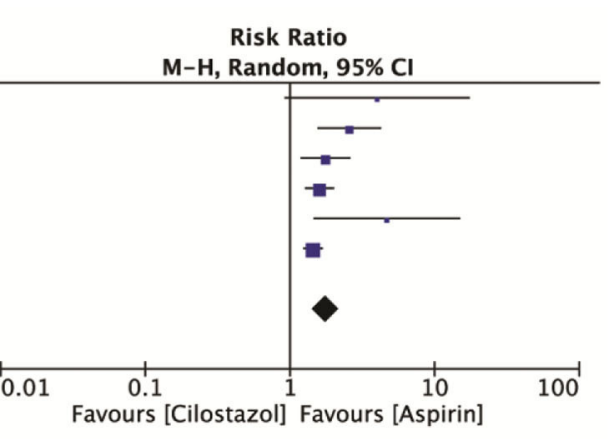

B

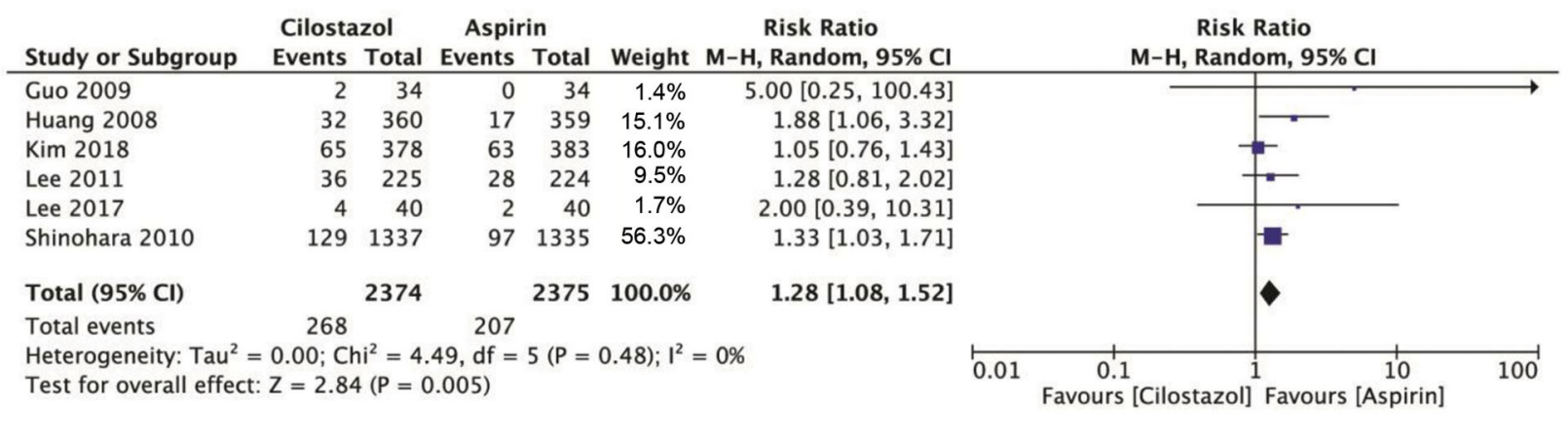

c

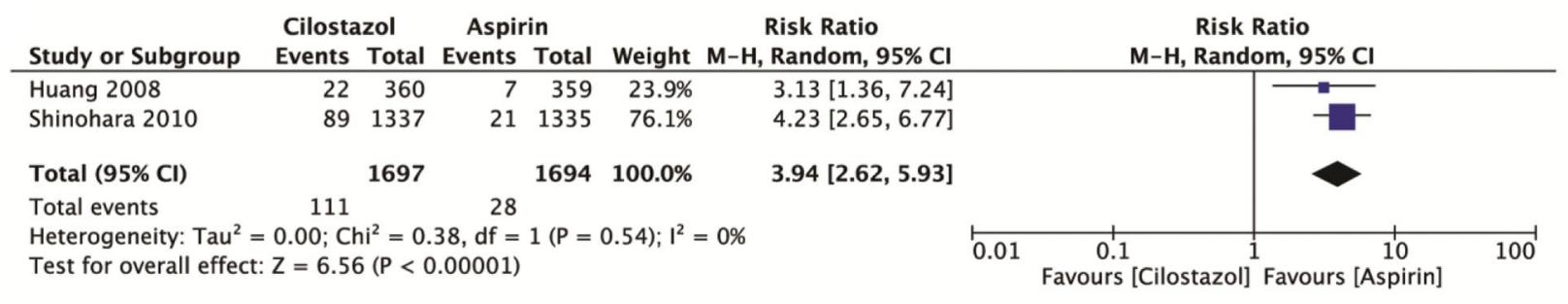

D

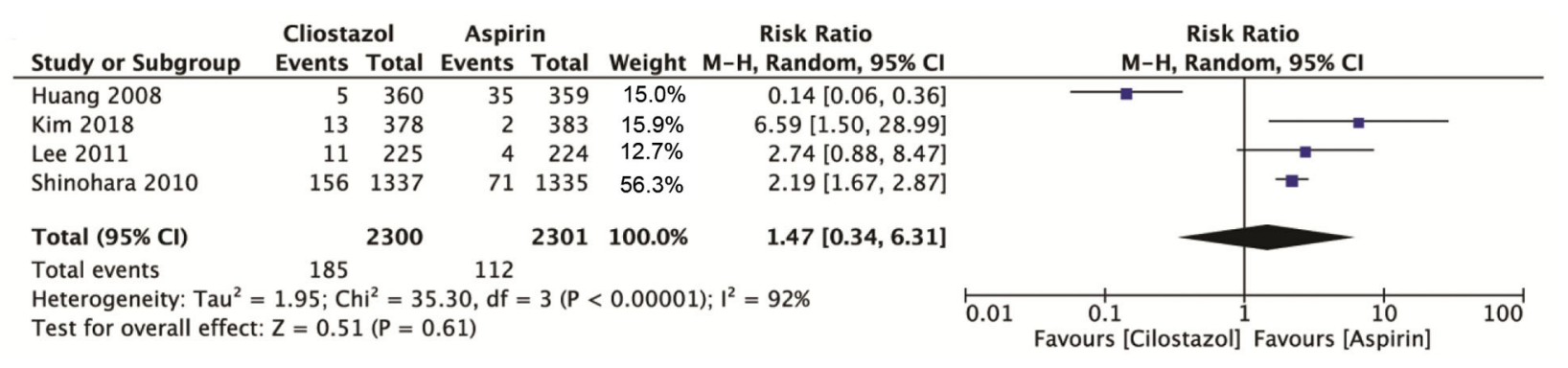

FIGURE 5 | (A) A forest plot of comparison: headache; (B) A forest plot of comparison: dizziness; (C) A forest plot of comparison: tachycardia; (D) A forest plot of comparison: palpitation.

Although current meta-analysis and previous studies have shown the effectiveness and relative safety of using cilostazol as secondary prevention of stroke, research also shows that, even in non-Asian populations, cilostazol may have a significant potential for secondary stroke prevention. Patients with bleeding tendencies, such as small vessel disease and numerous microbleeds, or those who have hemorrhagic strokes, are likely to benefit from cilostazol treatment (43). However, compared with Asians, cilostazol is relatively uncommon in Western populations. Several reasons may explain this uncommonness. First, intracranial atherosclerosis (ICAS) is the leading cause of stroke, and Asians more often have ICAS than Caucasians (44). Second, the absorption, metabolism, and excretion of cilostazol may be modified by race/ethnicity (45). For instance, common polymorphisms in the CYP2C19 gene for clopidogrel metabolism vary by race/ethnicity, noted 
in $\sim 30 \%$ of Caucasians, $40 \%$ of blacks, and more than $50 \%$ of East Asians (46). The pharmacogenetic of cilostazol is less well described, but it has been observed that genetic polymorphisms in CYP2C19 genes influence cilostazol pharmacokinetics (47). This is, therefore, possible that race/ethnicity may influence the effect of cilostazol on lowering ischemic stroke, ICH, and bleeding in non-Asian populations, but more studies are needed to examine how genetics and environment may affect the metabolism of cilostazol (18). Third, due to the lack of sufficient RCTs to study the effectiveness and safety of cilostazol as secondary prevention of stroke in Western populations, non-Asian physicians are not inclined to use cilostazol (44). Therefore, further pieces of research on the effect of cilostazol on different groups of people and ethnicity are needed.

The current meta-analysis has several limitations. First, the patients included in the studies were mainly from the Asian region, which will lead to regional deviations in the results. Largescale research is required to determine whether the researchers' results are valid and similar in non-Asian populations. Second, the present meta-analysis did not conduct subgroup analysis to assess the impact of time to randomization following a stroke and the length of time spent taking the research drug on effectiveness and safety outcomes. Also, sensitivity analysis was not performed. Third, the follow-up length is different, ranging from 3 months to 29 months. Finally, in MI, there was inter-study variability in the outcomes. Such inherent variations between the researchers' included trials, such as sample demographics, non-cardioembolic infarction inclusion/exclusion requirements, stroke occurrence, treatment, follow-up duration, drug compliance rates, and other factors, are not considered.

\section{REFERENCES}

1. Lee KW, Yusof Khan AHK, Ching SM, Chia PK, Loh WC, Abdul Rashid AM, et al. Stroke and novel coronavirus infection in humans: a systematic review and meta-analysis. Front Neurol. (2020) 11:579070. doi: 10.3389/fneur.2020.579070

2. Santoso A, Raharjo SB. Combination of oral anticoagulants and single antiplatelets versus triple therapy in nonvalvular atrial fibrillation and acute coronary syndrome: stroke prevention among Asians. Int J Angiol. (2020) 29:88-97. doi: 10.1055/s-0040-1708477

3. Shulga O, Bornstein N. Antiplatelets in secondary stroke prevention. Front Neurol. (2011) 2:36. doi: 10.3389/fneur.2011.00036

4. Shinohara Y, Katayama Y, Uchiyama S, Yamaguchi T, Handa S, Matsuoka $\mathrm{K}$, et al. Cilostazol for prevention of secondary stroke (CSPS 2): an aspirincontrolled, double-blind, randomised non-inferiority trial. Lancet Neurol. (2010) 9:959-68. doi: 10.1016/S1474-4422(10)70198-8

5. Huang Y, Cheng Y, Wu J, Li Y, Xu E, Hong Z, et al. Cilostazol as an alternative to aspirin after ischaemic stroke: a randomised, double-blind, pilot study. Lancet Neurol. (2008) 7:494-9. doi: 10.1016/S1474-4422(08)70094-2

6. Sandercock PA, Counsell C, Tseng MC, Cecconi E. Oral antiplatelet therapy for acute ischaemic stroke. Cochrane Database Syst Rev. (2014) 2014:CD000029. doi: 10.1002/14651858.CD000029.pub3

7. Lee SJ, Lee JS, Choi MH, Lee SE, Shin DH, Hong JM. Cilostazol improves endothelial function in acute cerebral ischemia patients: a double-blind placebo controlled trial with flow-mediated dilation technique. BMC Neurol. (2017) 17:169. doi: 10.1186/s12883-017-0950-y

\section{CONCLUSIONS}

Cilostazol is more effective than aspirin alone in reducing the recurrence rate of stroke without increasing the risk of bleeding and death. However, when using cilostazol, the significantly increased probability of adverse events cannot be ignored.

\section{DATA AVAILABILITY STATEMENT}

The original contributions presented in the study are included in the article/supplementary material, further inquiries can be directed to the corresponding author/s.

\section{AUTHOR CONTRIBUTIONS}

EC, JC, CL, XZ, ZF, and FT conceived and designed the study. JC, SY, KZ, and WL selected the studies and collected the data. EC, JC, ZX, YZ, and FT analyzed the data. EC and FT drafted and revised the article. All authors interpreted the results, read, and approved the final version of the manuscript.

\section{FUNDING}

This study was supported by the Key Laboratory of Cerebrovascular Disease of Gansu Province (No. 20JR10RA431), Innovation and Entrepreneurship Talent Project of Lanzhou (No. 2017-RC-57), National Natural Science Foundation of China (Nos. 81870329 and 81960673), Natural Science Foundation of Gansu Province (21JR1RA135), Cuiying Technological Innovation Foundation of Lanzhou University Second Hospital (CY2019-MS03), and Industrial Support Program for Colleges and Universities in Gansu Province (2020C-04).

8. Lee YS, Bae HJ, Kang DW, Lee SH, Yu K, Park JM, et al. Cilostazol in acute ischemic stroke treatment (CAIST Trial): a randomized double-blind noninferiority trial. Cerebrovasc Dis. (2011) 32:65-71. doi: 10.1159/000327036

9. McHutchison C, Blair GW, Appleton JP, Chappell FM, Doubal F, Bath $\mathrm{PM}$, et al. Cilostazol for secondary prevention of stroke and cognitive decline: systematic review and meta-analysis. Stroke. (2020) 51:237485. doi: 10.1161/STROKEAHA.120.029454

10. Albay CEQ, Leyson FGD, Cheng FC. Dual versus mono antiplatelet therapy for acute non- cardio embolic ischemic stroke or transient ischemic attack, an efficacy and safety analysis - updated meta-analysis. BMC Neurol. (2020) 20:224. doi: 10.1186/s12883-020-01808-y

11. Huang HP, Lin WH, Chen SG, Chen LZ, Chen MY, Che CH. Comparative efficacy and safety of nine anti-platelet therapies for patients with ischemic stroke or transient ischemic attack: a mixed treatment comparisons. Mol Neurobiol. (2017) 54:1456-66. doi: 10.1007/s12035-016-9739-z

12. Xie W, Zheng F, Zhong B, Song X. Long-term antiplatelet mono- and dual therapies after ischemic stroke or transient ischemic attack: network metaanalysis. J Am Heart Assoc. (2015) 4:e002259. doi: 10.1161/JAHA.115.002259

13. Moher D, Shamseer L, Clarke M, Ghersi D, Liberati A, Petticrew M, et al. Preferred reporting items for systematic review and meta-analysis protocols (PRISMA-P) 2015 statement. Syst Rev. (2015) 4:1. doi: 10.1186/2046-4053-4-1

14. Guyatt GH, Oxman AD, Santesso N, Helfand M, Vist G, Kunz R, et al. GRADE guidelines: 12. Preparing summary of findings tables-binary outcomes. J Clin Epidemiol. (2013) 66:158-72. doi: 10.1016/j.jclinepi.2012.01.012

15. Vallabhajosyula S, Jentzer JC, Geske JB, Kumar M, Sakhuja A, Singhal A, et al. New-onset heart failure and mortality in hospital 
survivors of sepsis-related left ventricular dysfunction. Shock. (2018) 49:144-9. doi: 10.1097/SHK.0000000000000952

16. Guo JJ, Xu E, Lin QY, Zeng GL, Xie HF. Effect of cilostazol on cerebral arteries in secondary prevention of ischemic stroke. Neurosci Bull. (2009) 25:383-90. doi: 10.1007/s12264-009-6192-2

17. Kim BJ, Lee EJ, Kwon SU, Park JH, Kim YJ, Hong KS, et al. Prevention of cardiovascular events in Asian patients with ischaemic stroke at high risk of cerebral haemorrhage (PICASSO): a multicentre, randomised controlled trial. Lancet Neurol. (2018) 17:509-18. doi: 10.1016/S1474-4422(18)30128-5

18. Lin MP, Meschia JF, Gopal N, Barrett KM, Ross OA, Ertekin-Taner $\mathrm{N}$, et al. Cilostazol versus aspirin for secondary stroke prevention: systematic review and meta-analysis. J Stroke Cerebrovasc Dis. (2021) 30:105581. doi: 10.1016/j.jstrokecerebrovasdis.2020.105581

19. Lee HL, Kim JT, Lee JS, Park MS, Choi KH, Cho KH, et al. Comparative effectiveness of dual antiplatelet therapy with aspirin and clopidogrel versus aspirin monotherapy in mild-to-moderate acute ischemic stroke according to the risk of recurrent stroke: an analysis of 15000 patients from a nationwide, multicenter registry. Circ Cardiovasc Qual Outcomes. (2020) 13:e006474. doi: 10.1161/CIRCOUTCOMES.119.006474

20. Kim JT, Kim BJ, Park JM, Lee SJ, Cha JK, Park TH, et al. Risk of recurrent stroke and antiplatelet choice in breakthrough stroke while on aspirin. Sci Rep. (2020) 10:16723. doi: 10.1038/s41598-020-73836-0

21. Dai Y, Ge J. Clinical use of aspirin in treatment and prevention of cardiovascular disease. Thrombosis. (2012) 2012:245037. doi: 10.1155/2012/245037

22. Fiolaki A, Katsanos AH, Kyritsis AP, Papadaki S, Kosmidou M, Moschonas IC, et al. High on treatment platelet reactivity to aspirin and clopidogrel in ischemic stroke: a systematic review and meta-analysis. J Neurol Sci. (2017) 376:112-6. doi: 10.1016/j.jns.2017.03.010

23. Geeganage CM, Diener HC, Algra A, Chen C, Topol EJ, Dengler $\mathrm{R}$, et al. Dual or mono antiplatelet therapy for patients with acute ischemic stroke or transient ischemic attack: systematic review and meta-analysis of randomized controlled trials. Stroke. (2012) 43:105866. doi: 10.1161/STROKEAHA.111.637686

24. Huang Y, Li M, Li JY, Li M, Xia YP, Mao L, et al. The efficacy and adverse reaction of bleeding of clopidogrel plus aspirin as compared to aspirin alone after stroke or TIA: a systematic review. PLoS ONE. (2013) 8:e65754. doi: 10.1371/journal.pone.0065754

25. Kheiri B, Osman M, Abdalla A, Haykal T, Swaid B, Ahmed S, et al. Clopidogrel and aspirin after ischemic stroke or transient ischemic attack: an updated systematic review and meta-analysis of randomized clinical trials. J Thromb Thrombolysis. (2019) 47:233-47. doi: 10.1007/s11239-018-1786-z

26. Lee M, Saver JL, Hong KS, Rao NM, Wu YL, Ovbiagele B. Risk-benefit profile of long-term dual- versus single-antiplatelet therapy among patients with ischemic stroke: a systematic review and meta-analysis. Ann Intern Med. (2013) 159:463-70. doi: 10.7326/0003-4819-159-7-201310010-00006

27. Paciaroni $\mathrm{M}$, Ince $\mathrm{B}, \mathrm{Hu} \mathrm{B}$, Jeng JS, Kutluk $\mathrm{K}$, Liu L, et al. Benefits and risks of clopidogrel vs. aspirin monotherapy after recent ischemic stroke: a systematic review and meta-analysis. Cardiovasc Ther. (2019) 2019:1607181. doi: 10.1155/2019/1607181

28. Zhou X, Tian J, Zhu MZ, He CK. A systematic review and meta-analysis of published randomized controlled trials of combination of clopidogrel and aspirin in transient ischemic attack or minor stroke. Exp Ther Med. (2017) 14:324-32. doi: 10.3892/etm.2017.4459

29. Johnston SC, Amarenco P, Denison H, Evans SR, Himmelmann A, James S, et al. Ticagrelor and aspirin or aspirin alone in acute ischemic stroke or TIA. $N$ Engl J Med. (2020) 383:207-17. doi: 10.1056/NEJMoa1916870

30. Weintraub WS. The vascular effects of cilostazol. Can J Cardiol. (2006) 22(Suppl B):56B-60. doi: 10.1016/S0828-282X(06)70987-4

31. Kalantzi K, Tentolouris N, Melidonis AJ, Papadaki S, Peroulis M, Amantos $\mathrm{KA}$, et al. Efficacy and safety of adjunctive cilostazol to clopidogreltreated diabetic patients with symptomatic lower extremity artery disease in the prevention of ischemic vascular events. J Am Heart Assoc. (2021) 10:e018184. doi: 10.1161/JAHA.120.018184

32. Higashi Y. Antiplatelet drugs and endothelial function. J Atheroscler Thromb. (2016) 23:1147-9. doi: 10.5551/jat.ED054

33. Tani T, Uehara K, Sudo T, Marukawa K, Yasuda Y, Kimura Y. Cilostazol, a selective type III phosphodiesterase inhibitor, decreases triglyceride and increases HDL cholesterol levels by increasing lipoprotein lipase activity in rats. Atherosclerosis. (2000) 152:299-305. doi: 10.1016/S0021-9150(99)00480-3

34. Douglas JS, Jr., Holmes DR, Jr., Kereiakes DJ, Grines CL, Block E, Ghazzal ZM, et al. Coronary stent restenosis in patients treated with cilostazol. Circulation. (2005) 112:2826-32. doi: 10.1161/CIRCULATIONAHA.104.530097

35. Shi L, Pu J, Xu L, Malaguit J, Zhang J, Chen S. The efficacy and safety of cilostazol for the secondary prevention of ischemic stroke in acute and chronic phases in Asian population-an updated meta-analysis. BMC Neurol. (2014) 14:251. doi: 10.1186/s12883-014-0251-7

36. Xue Y, Feng ZW, Li XY, Hu ZH, Xu Q, Wang Z, et al. The efficacy and safety of cilostazol as an alternative to aspirin in Chinese patients with aspirin intolerance after coronary stent implantation: a combined clinical study and computational system pharmacology analysis. Acta Pharmacol Sin. (2018) 39:205-12. doi: 10.1038/aps.2017.85

37. Gresele P, Momi S, Falcinelli E. Anti-platelet therapy: phosphodiesterase inhibitors. $\mathrm{Br} J$ Clin Pharmacol. (2011) 72:634-46. doi: 10.1111/j.1365-2125.2011.04034.x

38. Cone J, Wang S, Tandon N, Fong M, Sun B, Sakurai K, et al. Comparison of the effects of cilostazol and milrinone on intracellular cAMP levels and cellular function in platelets and cardiac cells. J Cardiovasc Pharmacol. (1999) 34:497-504. doi: 10.1097/00005344-199910000-00004

39. Kimura Y, Tani T, Kanbe T, Watanabe K. Effect of cilostazol on platelet aggregation and experimental thrombosis. Arzneimittelforschung. (1985) 35:1144-9.

40. Kamal AK, Naqvi I, Husain MR, Khealani BA. Cilostazol versus aspirin for secondary prevention of vascular events after stroke of arterial origin. Cochrane Database Syst Rev. (2011) 2011:CD008076. doi: 10.1002/14651858.CD008076.pub2

41. Uchiyama S, Shinohara Y, Katayama Y, Yamaguchi T, Handa S, Matsuoka K, et al. Benefit of cilostazol in patients with high risk of bleeding: subanalysis of cilostazol stroke prevention study 2. Cerebrovasc Dis. (2014) 37:296303. doi: $10.1159 / 000360811$

42. Tan CH, Wu AG, Sia CH, Leow AS, Chan BP, Sharma VK, et al. Cilostazol for secondary stroke prevention: systematic review and meta-analysis. Stroke Vasc Neurol. (2021) 6:410-23. doi: 10.1136/svn-2020-000737

43. Noma K, Higashi Y. Cilostazol for treatment of cerebral infarction. Expert Opin Pharmacother. (2018) 19:1719-26. doi: 10.1080/14656566.2018.1515199

44. Kim JS, Kwon SU, Uchiyama S. Cilostazol research in Asia: can it be applied to European and American patients? Int J Stroke. (2015) 10(Suppl 1):19. doi: $10.1111 /$ ijs. 12460

45. Kuehl P, Zhang J, Lin Y, Lamba J, Assem M, Schuetz J, et al. Sequence diversity in CYP3A promoters and characterization of the genetic basis of polymorphic CYP3A5 expression. Nat Genet. (2001) 27:383-91. doi: 10.1038/86882

46. Desta Z, Zhao X, Shin JG, Flockhart DA. Clinical significance of the cytochrome P450 2C19 genetic polymorphism. Clin Pharmacokinet. (2002) 41:913-58. doi: 10.2165/00003088-200241120-00002

47. Yoo HD, Park SA, Cho HY, Lee YB. Influence of CYP3A and CYP2C19 genetic polymorphisms on the pharmacokinetics of cilostazol in healthy subjects. Clin Pharmacol Ther. (2009) 86:281-4. doi: 10.1038/clpt.2009.90

Conflict of Interest: The authors declare that the research was conducted in the absence of any commercial or financial relationships that could be construed as a potential conflict of interest.

Publisher's Note: All claims expressed in this article are solely those of the authors and do not necessarily represent those of their affiliated organizations, or those of the publisher, the editors and the reviewers. Any product that may be evaluated in this article, or claim that may be made by its manufacturer, is not guaranteed or endorsed by the publisher.

Copyright $\odot 2022$ Chai, Chen, Li, Zhang, Fan, Yang, Zhao, Li, Xiao, Zhang and Tang. This is an open-access article distributed under the terms of the Creative Commons Attribution License (CC BY). The use, distribution or reproduction in other forums is permitted, provided the original author(s) and the copyright owner(s) are credited and that the original publication in this journal is cited, in accordance with accepted academic practice. No use, distribution or reproduction is permitted which does not comply with these terms. 